\title{
Sexual health for people with intellectual disability
}

\author{
Gillian Eastgate, MBBS, FRACGP(I)
}

\begin{abstract}
Eastgate G.
Sexual health for people with intellectual disability. Salud Publica Mex 2008;50 suppl 2:S255-S259.
\end{abstract}

\begin{abstract}
People with intellectual disability experience the same range of sexual needs and desires as other people. However, they experience many difficulties meeting their needs. They may be discouraged from relieving sexual tension by masturbating. They face a high risk of sexual abuse. They are likely not to be offered the full range of choices for contraception and sexual health screening. Poor education and social isolation may increase their risk of committing sexual offences. However, with appropriate education and good social support, people with intellectual disability are capable of safe, constructive sexual expression and healthy relationships. Providing such support is an essential part of supporting people with intellectual disability.
\end{abstract}

Key words: intellectual disability; sexuality; sexual abuse; contraception, sterilisation, pregnancy

\section{Eastgate G.}

Salud sexual para personas con discapacidad intelectual. Salud Publica Mex 2008;50 supl 2:S255-S259.

\section{Resumen}

Las personas con discapacidad intelectual experimentan el mismo rango de necesidades y deseos sexuales que las demás, sin embargo éstas encuentran muchas dificultades para satisfacer sus necesidades. En ocasiones se les desalienta de aliviar la tensión sexual mediante masturbación, corren un alto riesgo de sufrir abuso sexual y es muy probable que no se les ofrezcan todas las opciones de anticoncepción y exámenes de salud sexual. La escasa educación y el aislamiento social pueden aumentar el riesgo de que cometan infracciones sexuales. Sin embargo, con una educación apropiada y con un buen apoyo social las personas con discapacidad intelectual pueden encontrar relaciones saludables y una expresión sexual segura y constructiva. Parte esencial de la asistencia a las personas con discapacidad intelectual consiste precisamente en proporcionarles dicho apoyo.

Palabras clave: discapacidad intelectual; sexualidad; abuso sexual; anticoncepción; esterilización; embarazo
$\mathrm{P}$ eople with intellectual disability experience sexual needs and desires, just as do other people. However, they may not be able to communicate or act on these desires, and may struggle with learning appropriate sexual behaviour. They may also be hampered by the attitudes of other people. Beliefs persist in the community that people with intellectual disability are either childlike and asexual, or 'oversexed' and likely to become sex offenders. ${ }^{1}$

All adults have the right to form relationships, marry and have children. However, these things may be difficult or impossible for adults with intellectual disability because of inadequate community support, or because a person's own support needs are too high.

(I) Senior Lecturer, Queensland Centre for Intellectual and Developmental Disability, University of Queensland, Australia.

Accepted on: January 18, 2008

Address reprint requests to: Dr. Gillian Eastgate. Queensland Centre for Intellectual and Developmental Disability. Mater Misericordiae Hospital, Raymond Terrace, South Brisbane 4I0I, Australia.

E-mail: g.eastgate@uq.edu.au 
There are a number of sexual issues that are particularly relevant to people with intellectual disabilities. These will be outlined below.

\section{Sexual issues for people with intellectual disability}

\section{Masturbation}

Case study. Tom, 3I, is reported to masturbate 'all the time'. He often puts his hands down his pants while at the shops, and has been seen at home rubbing his penis on the carpet.Tom has moderate intellectual disability and only speaks and understands a few words.

Masturbation is the main sexual expression and means of relief available to many people with intellectual disability. ${ }^{2}$ This is often seen as a problem, but it is a normal and natural experience for women and men of all ages. ${ }^{1}$ However a number of difficulties may arise including:

1. Masturbation in public places.

2. Very frequent or prolonged masturbation, often without climax.

3. Practices that may cause injury.

There are very few reports of masturbation techniques being taught, but there is one example that suggests that even people with severe disabilities may be taught to masturbate safely and effectively. ${ }^{2}$ Education to encourage masturbation only in appropriate places can be provided as part of a broader programme to encourage appropriate behaviour in public places.

\section{Sexual abuse}

Case study. Susie, 22, loves to go dancing. However, for the last two weeks she has refused to go, becoming very upset. She has been very reluctant to say why but has finally told her mother that last time she went 'a boy' touched her 'down there'.

Both males and females with intellectual disability are at higher risk of sexual abuse than other people in the community. ${ }^{3}$ This abuse may come from family members, support workers or co-clients in housing or work situations. As in people without disabilities, sexual abuse results in a range of emotional disturbances such as anxiety and depression. A person with intellectual disability may express this by means of self-injurious behaviour, inappropriate sexual behaviour or even reduced cognitive functioning. ${ }^{4}$

People with intellectual disability often lack knowledge about what behaviours are appropriate, and may lack the communication skills to report abuse. ${ }^{5}$
Therefore those cases that are reported are probably only a small proportion of the abuse that is occurring. Still less cases of serious sexual abuse or assault are actually dealt with by the courts. ${ }^{6,7}$ However, a person with limited communication skills can be assisted by the use of dolls, drawings or models. As with abuse in children, this needs to be performed by a person with appropriate skills and training to avoid leading questions. ${ }^{3}$ If appropriate methods are used, even a person with severe disability may be able to report abuse and make decisions about how to proceed. ${ }^{7}$

The best protection has been shown to be sexual abuse knowledge ${ }^{5}$ so there is a very real place for education programmes to reduce the risk of sexual abuse.

\section{Sexual offending}

Case study. Mark, 16, attends Special School.A younger boy has told a teacher that Mark took him to the toilets and made the younger boy suck his penis. Mark admits that he did this but can't see why it is a problem.

Intellectual disability itself does not increase the risk of committing a sexual offence. However, people with intellectual disability may have risk factors for offending:

1. Past experience of sexual abuse (see above).

2. Poor access to education and information about what constitutes appropriate sexual behaviour.

3. Difficulty learning the social rules of sexual behaviour.

4. Social isolation and lack of opportunity for appropriate sexual relationships.

Many such offences could be prevented by adequate protection from sexual abuse, appropriate education and social integration.

When a person with intellectual disability does commit an offence, intensive education using modified cognitive behavioural therapy can markedly reduce the rate of re-offending. ${ }^{8}$

\section{Consent to sexual activity}

Case study. Maria, 37, has been coming home quite late from work. When asked why, she admits that she has been meeting a man in the park on the way home and has been having sex with him. When asked whether she wants to have sex with this man, she doesn't seem quite sure.

Very little has been written regarding consent to sexual activity for people with intellectual disability. In many places there is a widespread misperception that 
a person with intellectual disability should not have sexual relationships, or even that such relationships are illegal.

The main difficulty for a person with intellectual disability is determining whether the person has the capacity to consent to a sexual relationship and if so, whether the person is consenting to a particular relationship. In particular, the lack of power many people with disabilities experience in their relationships generally may make it difficult to be sure whether consent is truly given. $^{7}$

As a parallel, it may be useful to consider the issues that need to be considered when assessing a person's capacity to make other complex decisions, such as consenting to medical treatment. In a medical situation, a person needs to be able to:

1. Receive, comprehend, retain and recall relevant information.

2. Integrate the information received and relate it to one's situation.

3. Evaluate benefits and risks in terms of personal values.

4. Select an option and give cogent reasons for the choice.

5. Communicate one's choice to others.

6. Persevere with that choice, at least until the decision is acted upon. ${ }^{9}$

In a sexual situation, relevant information would include an understanding of sexual intercourse and other sexual behaviours, and an awareness of the risk of pregnancy and sexually transmitted infections.

\section{Contraception}

Case study. Anna, 24, has admitted to her mother that she has had sex with Leonard, a young man at work. Anna says that she enjoys having sex and intends to do it again. Anna's mother accepts that it is Anna's choice to have sex, but is worried about Anna becoming pregnant. Anna says she does not want to have a baby, at least not yet.

A woman with intellectual disability has the same choices as any other woman making a decision about contraception. However, contraceptive methods may need to be explained in a simple way:

1. The oral contraceptive pill can be taken by most women with intellectual disability. Support is likely to be needed to ensure it is taken regularly. Some medications for epilepsy interact with the oral contraceptive pill. The risk of deep venous thrombosis is increased so it may not be suitable for women with impaired mobility. ${ }^{10}$

2. Depot medroxyprogesterone acetate (DMPA) has been used extensively and often controversially in women with intellectual disability. It is a highly effective contraceptive which also suppresses menstruation in many women. However, it is also known to cause osteopenia and weight gain ${ }^{11}$ so long term use needs careful consideration.

3. Etonogestrel subdermal implants may also be useful. These cause less weight gain and osteopenia, but more menstrual irregularity.

4. Intrauterine devices (IUCDs). The newer progesterone-containing IUCDs give effective long term contraception and markedly reduced menstruation. With appropriate explanation and consent they may be suitable for women with intellectual disability, but general anaesthesia may be needed for insertion.

5. Barrier methods (condoms and diaphragms) may be particularly difficult to understand and use effectively for people with intellectual disability. Condoms may help to reduce the risk of sexually transmitted infection, but may be best when added to another, more reliable, method of contraception.

In practice, women with intellectual disability are more likely to be treated with sterilisation or DMPA than other methods of contraception. ${ }^{12}$ However, health professionals have a responsibility to offer all relevant options, and to treat the woman as an individual.

\section{Sexually transmitted infection}

Case study. Rachel, 26, has mild intellectual disability and a mental illness. She has a boyfriend but recently she had a fight with him and went home from a bar with another man. She admits that she had sex with this man, partly to annoy her boyfriend. She doesn't think he used a condom.

Very little information is available regarding sexually transmitted infections in people with intellectual disability. However, it is reasonable to assume that people with intellectual disability who are sexually active are at risk of the same range of sexually transmitted infection as other people in the community.

The risk of infection may be higher for a sexually active person with intellectual disability because:

1. The person may not know about sexually transmitted infections.

2. The person may not be able to buy condoms, or to get help to obtain them. 
3. The person may not have the skills to negotiate condom use.

A person with an intellectual disability may experience difficulty accessing sexual health clinics, communicating the need for screening or understanding the need for testing. The person's family or other support people may not be aware of their sexual activity and need for sexual health screening. Their sexual contact may be hidden, as in cases of sexual abuse, so infections may go undetected. There is a need for awareness on the part of health professionals of the possible need for screening.

When the need for screening is identified, there may be difficulty in assuring informed consent and understanding of the pre-test counselling usually offered as part of a sexual health screen. Consent and cooperation with the necessary intimate physical examination may also present difficulties. There is a need for sexual health services to gain some expertise in dealing with people with intellectual disability.

\section{Menstrual management and sterilisation}

Case study. Laura, 19, has moderate intellectual disability. She presents with her mother, who wants her to have a hysterectomy. Her mother says that Laura makes a mess with her pads at period time, and she is worried about sexual abuse and resulting pregnancy.

Several decades ago sterilisation of women with intellectual disability was widespread, often performed before puberty and usually involving hysterectomy. However, more recently there has been outrage at this practice. ${ }^{13,14}$ In many countries strict controls have been placed on sterilisation for people with disability.

Sterilisation and hysterectomy in most cases are reserved for genuine medical indications, or when all less restrictive options have been tried and failed. ${ }^{10}$ However, there are many reports of such sterilisations occurring, and the appropriateness and effectiveness of the laws has been questioned. ${ }^{14-16}$

It is important that Laura's mother is informed that hysterectomy will not protect Laura from sexual abuse. In fact, it may increase her risk because the perpetrator may perceive that there is less risk of being caught.

Treatment is often requested to stop menstruation in women with intellectual disability on the grounds that their menstruation is a hygiene problem. The same women often need assistance with management of urination and defaecation, and this is not questioned but accepted as normal bodily function. Most women can learn to manage their own menstruation with appropriate education and support. Menstrual suppression should only be considered when other options have failed, or if there are significant gynaecological or other medical indications. The exception to this is when the woman herself requests such treatment and can demonstrate that she is capable of making an informed decision. ${ }^{10}$

If a decision is made to use menstrual suppression, the methods available include:

1. The oral contraceptive pill (see above) taken continuously.

2. Depot medroxyprogesterone acetate (DMPA) (see above) suppresses menstruation in about two thirds of women.

3. The progesterone-containing IUCD (see above) stops menstruation in about $20 \%$ of women, and makes the periods lighter in many others.

All of these methods are reversible, so do not have the legal significance of permanent procedures. However, it is still important to make sure that the woman and her family are fully informed of the choices available, and the advantages and disadvantages of each.

\section{Pregnancy and child rearing}

Case study. Sally, 27, is brought in by her mother because she has not had a period for two months.A pregnancy test is positive. Sally admits that she has a boyfriend at the café she works at. Like Sally, he has a mild intellectual disability. Sally understands that this test means she is going to have a baby. She is pleased, but her mother is not.

People with intellectual disability are legally assumed to have the same rights as anyone else when making decisions about pregnancy and child rearing. However, a person with intellectual disability faces many difficulties in raising children. The main burden is likely to fall on their families, who may not be willing or able to offer the level of support needed. The family may find it very difficult to accept that their adult child with an intellectual difficulty is or has been sexually active.

In countries where abortion is readily available, Sally may be pressured to have an abortion by her family, even if she herself wants to have the baby. It is important to ascertain what Sally wants, whether she is realistic about motherhood, and whether support is available to help her raise her child.

If Sally continues the pregnancy, a number of issues need to be considered:

1. Intensive support is likely to be needed, particularly when both parents have intellectual disability. 
2. Depending on the cause of the parents' disabilities, their children may be at increased risk of having intellectual disability. ${ }^{17}$

3. Children of parents with intellectual disability may face discrimination, isolation and difficulty with school achievement, even if they themselves do not have intellectual disability. Despite this, such children are usually positive about their parents.

4. Parents with intellectual disability are likely to face financial difficulty while raising children, since most hold low paid, if any, employment. ${ }^{18}$

5. It is important that Sally has information about and access to contraception after she has the baby. The reality of birth and child rearing may encourage her to prevent further pregnancies, which would make it easier to support her and her child.

\section{Summary}

People with intellectual disability face a wide range of issues related to their sexuality. Community attitudes make it especially difficult for them to achieve appropriate sexual expression. However, for most of the issues, appropriate education and adequate social support can markedly improve their situation. It is vital for health professionals to provide appropriate treatment, and to encourage the provision of appropriate supports.

\section{References}

I. Sexuality. In Lennox N, ed. Management Guidelines: Developmental Disability. Therapeutic Guidelines Limited: Melbourne, 2005:183-189. 2. Kaeser F, O'Neill J.Task analyzed masturbation instruction for a profoundly retarded adult male: a data based case study. Sex Disabil 1987;8(I):17-24.
3.Valenti-Hein, D. Use of visual tools to report sexual abuse for adults with mental retardation. Ment Retard 2002 40(4):297-303.

4. Mansell S, Sobsey D, Moskal R. Clinical findings among sexually abused children with and without developmental disabilities. Ment Retard 1998;36(I):12-22.

5. Tang C, Lee Y. Knowledge on sexual abuse and self-protection skills: a study on female Chinese adolescents with mild mental retardation. Child Abuse Negl 1999;23(3):269-279.

6. Carmody M. Invisible victims: sexual assault of people with an intellectual disability. Australian and New Zealand Journal of Developmental Disabilities 1991;17(2):229-236.

7. O'Hara J, Martin H.A learning-disabled woman who had been raped: a multi-agency approach. J R Soc Med 200 I;94:245-246.

8. Lindsay W, et al.Treatment of adolescent sex offenders with intellectual disabilities. Ment Retard 1999;37(3):20I-2II.

9. Wong J, et al.The capacity of people with a "mental disability" to make a health care decision. Psychol Med 2000;30:295-306.

I0.Women's Health. In Lennox N, ed. Management Guidelines: Developmental Disability. Therapeutic Guidelines Limitied: Melbourne, 2005:191-201.

II.Westhoff C. Depot-medroxyprogesterone acetate injection (DepoProvera): a highly effective contraceptive option with proven long-term safety. Contraception 2003;68(2):75-87.

12. Servais L, et al. Contraception of women with intellectual disability: prevalence and determinants. Intellect Disabil Res 2002;46(2): 108-I I9. 13. Pandya S. Medical Council of India on hysterectomy in the mentally retarded. Natl Med J India 1997;10(I):36.

14. Dorozynski A. France to investigate illegal sterilisation of mentally ill patients. Br Med J 1997;3 15:697.

15. Keywood K. Hobson's choice: reproductive choices for women with learning disabilities. Med Law 1998; 17: 149-165.

16. Dorozynski A. Sterilisation of I4 mentally handicapped women challenged. Br Med J 2000;321:721.

17. Quilliam S, Dalrymple J,Whitmore J. A low-IQ couple wanting children. Practitioner 2001;245:359-374.

18. Booth T, Booth W. Against the odds: growing up with parents who have learning difficulties. Ment Retard 2000;38(I): I-I4. 